\title{
Analisa QoS (Quality of Service) Zeroshell pada Mekanisme Load Balancing dan Failover
}

\author{
Praja Risnaldy, Indri Neforawati \\ Program Studi Teknik Multimedia dan Jaringan \\ Jurusan Teknik Informatika dan Komputer \\ Politeknik Negeri Jakarta \\ Depok, Indonesia \\ praja.risnaldy.tik16@mhsw.pnj.ac.id, indri.neforawati@tik.pnj.ac.id
}

Diterima : 15 April 2020. Disetujui: 22 Mei 2020. Dipublikasikan: 26 Mei 2020

\begin{abstract}
The bandwidth requirements are increasing along with the number of internet users are increasing. The problem that is often faced by users in accessing the internet is ISPS(Internet Service Provider) are often down and internet connections tend to be slow. So, it is necessary to hold a multi-connection using two different ISPs by utilizing load balancing and failover. Load balancing and failover are implemented in zeroshell 3.9.3 using the weight round-robin method. Testing is done with an internet speed tester, downloading videos from YouTube, and disconnecting one of the connection lines. Testing with Internet speed tester is to get the throughput value of systems with load balancing and systems without load balancing. Video download testing is done to get the QoS value, namely throughput, packet loss, delay, and jitter. Testing by disconnecting one of the connection lines to get the function of failover as well as calculating the delay value of the connection line transfer. The result is that load balancing and failover systems can function on zeroshell, systems that implement load balancing have higher throughput values compared to ISP 1 and ISP 2 which do not implement load balancing systems, the value of throughput, packet loss, and delay has a "very good" TIPHON category with index 4, jitter value has a "good" TIPHON category with index 3, and delay value of failover system has a "bad" TIPHON category with index 1 .
\end{abstract}

Keywords: Failover; Load Balancing; QoS; Zeroshell

Abstrak - Kebutuhan bandwidth semakin hari semakin meningkat seiring bertambahnya jumlah pengguna internet. Masalah yang sering dihadapi pengguna dalam mengakses internet adalah ISP yang sering down dan koneksi internet yang cenderung lambat. Sehingga, perlu diadakan multikeneksi menggunakan dua ISP yang berbeda dengan pemanfaatan load balancing dan failover. Load balancing dan failover diimplementasikan pada zeroshell 3.9.3 dengan metode weight roundrobin. Pengujian dilakukan dengan internet speed tester, download video dari YouTube, serta memutuskan salah satu jalur koneksi. Pengujian dengan internet speed tester untuk mendapatkan nilai throughput dari sistem load balancing dan sistem tanpa load balancing. Pengujian download video dilakukan untuk mendapatkan nilai QoS, yaitu throughput, packet loss, delay, dan jitter. Pengujian dengan memutuskan salah satu jalur koneksi untuk mendapatkan fungsi dari failover sekaligus menghitung nilai delay dari perpindahan jalur koneksi. Hasil penelitian ini adalah sistem load balancing dan failover dapat berfungsi pada zeroshell, sistem yang menerapkan load balancing memiliki nilai throughput yang lebih tinggi dibandingkan dengan ISP 1 dan ISP 2 yang tidak menerapkan sistem load balancing, nilai QoS throughput, packet loss, dan delay memiliki kategori TIPHON "sangat bagus" dengan indeks 4, nilai QoS jitter memiliki kategori TIPHON "bagus" dengan indeks 3, serta nilai delay sistem failover memiliki kategori TIPHON “Jelek” dengan indeks 1.

Kata Kunci: Failover; Load Balancing; QoS; Zeroshell

\section{PENDAHULUAN}

Internet menjadi tempat bagi setiap pengguna untuk saling terhubung dalam jaringan yang sangat luas [1]. Untuk bisa menggunakan internet dibutuhkan ISP (Internet Service Provider) sebagai penyedia layanan internet, baik untuk sambungan lokal maupun internasional. Sambungan lokal menyediakan interkoneksi antar ISP di Indonesia agar dapat saling terhubung satu sama lain, sedangkan sambungan internasional menyediakan bandwidth yang dapat digunakan untuk terhubung ke backbone internasional [2].
Kebutuhan bandwidth semakin hari semakin meningkat seiring bertambahnya jumlah pengguna internet. Tahun 2005 sampai tahun 2019 jumlah pengguna internet di dunia selalu bertambah setiap tahun [3]. Jumlah pengguna di Asia pada pertengahan tahun 2019 sebanyak 55\% dari total seluruh pengguna internet di dunia yang berjumlah kurang lebih 4,5 miliar [4]. Peningkatan jumlah pengguna internet tidak didukung dengan mutu jaringan internet yang sebanding [5]. Masalah yang sering dihadapi pengguna untuk mengakses internet adalah ISP yang sering down dan koneksi internet yang cenderung lambat. Sehingga, perlu diadakan multi koneksi menggunakan dua jalur ISP yang 
berbeda untuk dapat digunakan secara bersamaan agar didapat bandwidth yang besar demi memenuhi kebutuhan internet yang besar dengan memanfaatkan mekanisme load balancing dan failover [6].

Load balancing berfungsi agar trafik dapat berjalan lebih baik, memaksimalkan throughput, memperkecil delay, dan menghindari overload pada salah satu jalur koneksi [7]. Failover berfungsi agar jalur koneksi tetap tersedia jika terjadi gangguan pada jalur koneksi utama. Implementasi load balancing dan failover diterapkan pada zeroshell yang merupakan routerOS berbasis linux. Zeroshell digunakan karena memiliki beberapa fitur, seperti load balancing dan failover serta dalam menjalankan zeroshell dibutuhkan spesifikasi hardware yang kecil, minimum requirements hardware [8].

Penelitian mengenai load balancing dan failover sudah cukup banyak dilakukan, seperti penelitian mengenai implementasi load balancing dua ISP menggunakan mikrotik [9], implementasi high availability server menggunakan metode load balancing dan failover [10], implementasi load balancing dan failover berbasis mikrotik router [6], dan penelitian mengenai aplikasi load balancing dengan metode Nth [7].

Penelitian-penelitian tersebut membahas tentang implementasi load balancing dan failover. Penelitian ini juga membahas hal yang sama, namun diimplementasikan pada zeroshell sekaligus dilakukan analisis QoS (Quality of Service) yang akan disesuaikan dengan standar TIPHON. Tujuan penelitian ini adalah mengevaluasi kualitas jaringan pada load balancing dan failover dengan analisis QoS pada Zeroshell.

\section{TINJAUAN PUSTAKA}

\section{A. Load Balancing}

Load Balancing berfungsi agar trafik dapat berjalan lebih baik, memaksimalkan throughput, memperkecil delay, dan menghindari overload pada salah satu jalur koneksi [7]. Throughput, performance, scalability, waktu respon, pemanfaatan sumber daya, dan fault tolerance adalah beberapa parameter pengukuran yang dapat digunakan untuk mengevaluasi load balancing [11].

Hingga saat ini, terdapat berbagai macam algoritma untuk load balancing, seperti round-robin, least-connection, dan least loaded. Round-robin merupakan algoritma load balancing yang dilakukan dengan memberi giliran masing-masing switch atau router secara berurutan dan sirkular, sehingga tidak mementingkan beban traffic dari setiap switch atau router. Least connection bekerja dengan memilih switch atau router dengan koneksi outgoing (keluar) yang paling rendah. Sedangkan least loaded akan memilih switch atau router dengan beban kerja yang paling rendah [1].

\section{B. Failover}

Failover merupakan kemampuan sistem untuk dapat berpindah gateway secara manual maupun otomatis jika salah satu gateway mengalami masalah sehingga dapat menjadi backup untuk sistem yang mengalami masalah dalam mengakses internet [8].

\section{C.Zeroshell}

Zeroshell adalah distribusi berbasis Linux yang didedikasikan untuk implementasi router dan firewall yang sepenuhnya dapat diatur melalui antarmuka web. Fitur yang disediakan antara lain load balancing dan failover untuk beberapa koneksi internet, VPN Site to Site dan VPN Host to Site, captive portal untuk hotspot, firewall, QoS, autentikasi dan akuntansi RADIUS, hingga pelacakan, dan pencatatan koneksi jaringan [12].

Zeroshell memiliki fitur untuk menyeimbangkan trafik yang dilalui, NetBalancer. NetBalancer adalah fitur dari zeroshell yang dapat memanfaatkan beberapa gateway internet menjadi seimbang, fitur ini disebut juga dengan load balancing. Load balancing pada zeroshell menggunakan metode weight round robin [8].

Metode weight round robin didasari oleh round-robin scheduling. Weight round robin merupakan teknik penjadwalan yang dapat diterapkan dalam berbagai bidang untuk pemakaian sumber daya bersama-sama pada sebuah komputer atau jaringan. Zeroshell ditujukan untuk server dan perangkat embedded agar dapat membuat layanan jaringan menjadi lebih baik [8].

\section{D.Parameter QoS}

Parameter QoS yang digunakan:

\section{Throughput}

Throughput adalah kecepatan (rate) transfer data efektif, yang diukur dalam bps. Throughput merupakan jumlah total kedatangan paket yang sukses, diamati pada tujuan selama interval waktu tertentu dibagi oleh durasi interval waktu tersebut [13].

\begin{tabular}{ccc}
\multicolumn{3}{c}{ TABEL I. THROUGHPUT VERSI TIPHON } \\
\hline Kategori & Throughput (bps) & Indeks \\
\hline Sangat Bagus & 100 & 4 \\
\hline Bagus & 75 & 3 \\
\hline Sedang & 50 & 2 \\
\hline Jelek & $<25$ & 1 \\
\hline
\end{tabular}

\section{Delay (latency)}

Delay adalah waktu yang dibutuhkan data untuk menempuh jarak dari asal ke tujuan. Delay dapat dipengaruhi oleh jarak, media fisik, kongesti, atau waktu proses yang lama [13]. 
TABEL II. DELAY VERSI TIPHON

\begin{tabular}{ccc}
\hline Kategori & Delay $(\mathrm{ms})$ & Indeks \\
\hline Sangat Bagus & $<150$ & 4 \\
\hline Bagus & $150 \mathrm{~s} / \mathrm{d} 300$ & 3 \\
\hline Sedang & $300 \mathrm{~s} / \mathrm{d} 450$ & 2 \\
\hline Jelek & $<450$ & 1 \\
\hline
\end{tabular}

\section{Packet loss}

Packet loss merupakan persentase hilangnya paket saat pengiriman data [13].

\begin{tabular}{ccc} 
TABEL & III. PACKET LOSS VERSI TIPHON & \\
\hline Kategori & Packet Loss $(\%)$ & Indeks \\
\hline Sangat Bagus & 0 & 4 \\
\hline Bagus & 3 & 3 \\
\hline Sedang & 15 & 2 \\
\hline Jelek & 25 & 1 \\
\hline
\end{tabular}

\section{Jitter}

Jitter diakibatkan oleh variasi-variasi dalam panjang antrean, dalam waktu pengolahan data, dan juga dalam waktu penghimpunan ulang paket di akhir perjalanan jitter. Jitter lazimnya disebut variasi delay [13].

\begin{tabular}{ccc}
\multicolumn{3}{c}{ TABEL IV. JITTER VERSI TIPHON } \\
\hline Kategori & Jitter $(\mathrm{ms})$ & Indeks \\
\hline Sangat Bagus & 0 & 4 \\
\hline Bagus & $0 \mathrm{~s} / \mathrm{d} 75$ & 3 \\
\hline Sedang & $75 \mathrm{~s} / \mathrm{d} 125$ & 2 \\
\hline Jelek & $125 \mathrm{~s} / \mathrm{d} 225$ & 1 \\
\hline
\end{tabular}

\section{METODE PENELITIAN}

Metode penelitian yang dilakukan secara bertahap dan saling berkaitan satu sama lain pada penelitian ini, yaitu:

\section{Pengumpulan Data}

Metode pengumpulan data pada penelitian ini dilakukan dengan metode literatur dan eksperimen. Metode literatur dilakukan dengan cara membaca dan membandingkan referensi tentang QoS, load balancing, failover, zeroshell, dan referensi lain yang terkait. Metode eksperimen dilakukan dengan cara melakukan penelitian secara langsung terhadap objek yang diteliti dengan melakukan pengujian load balancing dan failover.

\section{Perancangan}

Perancangan dilakukan untuk mendapatkan rancangan sistem yang akan diimplementasikan pada tahap implementasi. Rancangan sistem berupa diagram blok untuk sistem load balancing dan failover pada zeroshell.

3. Implementasi

Implementasi dilakukan sesuai dengan rancangan sistem yang telah ditentukan pada tahap perancangan.

\section{Pengujian}

Pengujian dilakukan setelah implementasi sistem berhasil dilakukan. Pengujian pada sistem dilakukan dengan 3 cara, yaitu pengujian dengan internet speed tester, pengujian dengan download video, serta pengujian dengan melalukan ping kemudian mematikan salah satu jalur koneksi.

\section{PERANCANGAN}

Dua ISP yang berasal dari dua modem yang berbeda menjadi penyedia internet yang akan diakses oleh PC client melalui laptop. PC zeroshell mengatur koneksi client dengan dua ISP menggunakan mekanisme load balancing dan failover.

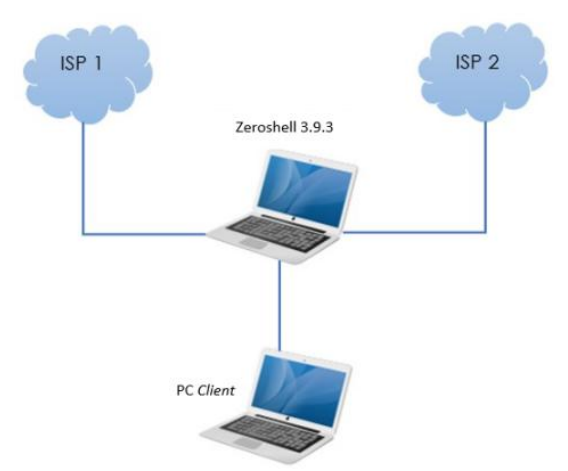

Gambar 1. Diagram Blok Load Balancing dan Failover

Gambar 1 merupakan diagram blok dari load balancing dan failover pada zeroshell di mana zeroshell 3.9.3 diterapkan sebagai load balancer dan failover.

\section{IMPLEMENTASI}

A.Hardware untuk Load Balancing dan failover

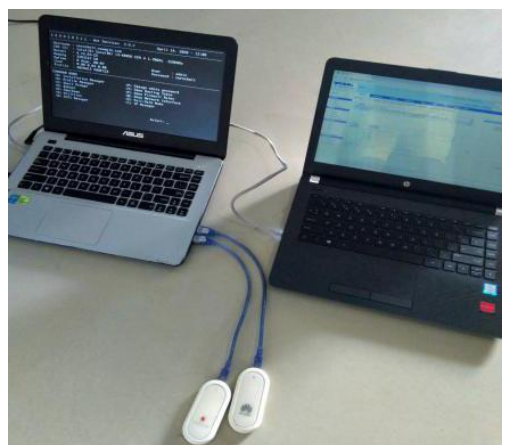

Gambar 2. Hardware untuk Load Balancing dan Failover

Gambar 2 merupakan rangkaian hardware yang digunakan untuk load balancing dan failover pada zeroshell. Berikut penjelasan hardware yang digunakan:

1. PC zeroshell, laptop yang dipasang zeroshell 3.9.3. Laptop yang digunakan adalah Asus dengan RAM 10 GB. 
2. Dua modem GSM Huawei E220 menggunakan kartu Telkomsel sebagai ISP 1 dan kartu Tri sebagai ISP 2.

3. PC client, laptop yang terhubung dengan PC zeroshell menggunakan kabel LAN.

\section{B.Pengaturan IP Address}

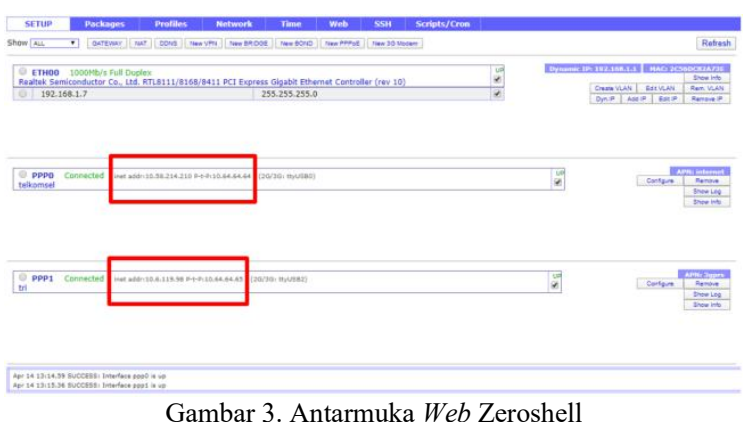

Gambar 3 merupakan antarmuka web zeroshell. Terdapat 3 interface yang digunakan, yaitu:

1. ETH00, PC client yang terhubung dengan PC zeroshell.

2. PPP0, GSM Huawei E220 menggunakan kartu Terkomsel dan berada di USB 2 sebagai ISP 1 dengan IP address dynamic,

3. PPP1, GSM Huawei E220 menggunakan kartu Tri dan berada di USB 1 sebagai ISP 2 dengan IP address dynamic.

\section{Pengaktifan DHCP Server}

Fungsi DHCP server adalah pada saat penambahan PC client, tidak perlu melakukan konfigurasi IP address secara manual karena IP address akan didapat secara otomatis sesuai range yang sudah diatur.

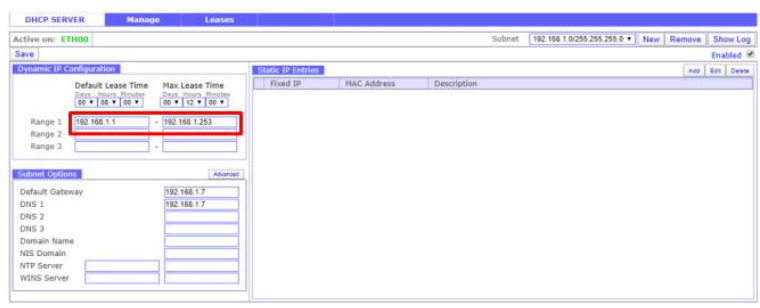

Gambar 4. DHCP Server pada Zeroshell

Gambar 4 merupakan range untuk Dynamic IP, yaitu 192.168.1.1 - 192.168.1.253.

\section{D.Pengaktifan Net Balancer}

NetBalancer menggunakan algoritma weight round-robin, menimbang dari beban pada gateway. Failover memindahkan gateway ketika terjadi masalah pada salah satu gateway.

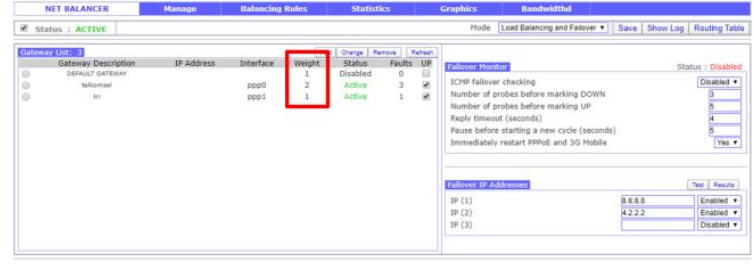

Gambar 5. Net Balancer pada Zeroshell

E. Pengaktifan NAT

NAT diatur untuk menghubungkan PC client dengan internet.

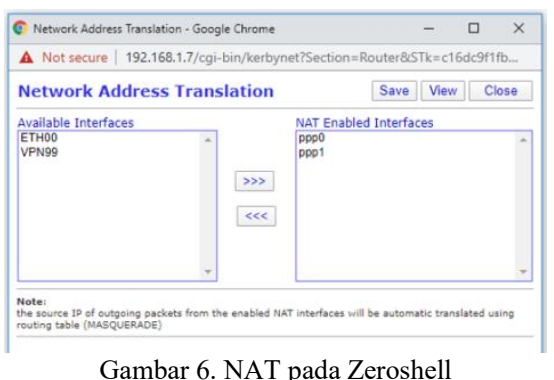

\section{PENGUJIAN}

Pengujian load balancing pada zeroshell dilakukan dengan menguji kecepatan internet melalui situs internet speed tester, yaitu situs speedtest.cbn.id dan speedtest.net. Selain melakukan pengujian kecepatan internet, pengujian load balancing juga dilakukan dengan cara melakukan download video yang berukuran 61,1 MB dari YouTube. Selama proses download berlangsung, dilakukan capture packet menggunakan aplikasi wireshark untuk menghitung nilai throughput, packet loss, delay, dan jitter.

Pengujian failover dilakukan dengan melalukan ping kemudian mematikan salah satu jalur koneksi atau ISP untuk mendapatkan fungsi dari failover. Selama proses ping berlangsung, dilakukan capture packet menggunakan aplikasi wireshark untuk menghitung nilai delay. Masingmasing pengujian dilakukan sebanyak lima kali untuk mendapatkan hasil pengujian yang optimal.

\section{A.Hasil Pengujian Load Balancing Menggunakan Internet Speed Test}

Pengujian pertama dilakukan dengan menguji kecepatan internet melalui situs speedtest.cbn.id sebanyak lima kali. Selanjutnya dilalukan pengujian kecepatan internet melalui situs speedtest.net sebanyak lima kali. Data yang didapat berupa kecepatan internet di setiap pengujian (throughput). Data hasil pengujian pada situs internet speed tester 
dijumlahkan, lalu dibagi dengan banyak pengujian yang dilakukan untuk mendapat rata-rata throughput.

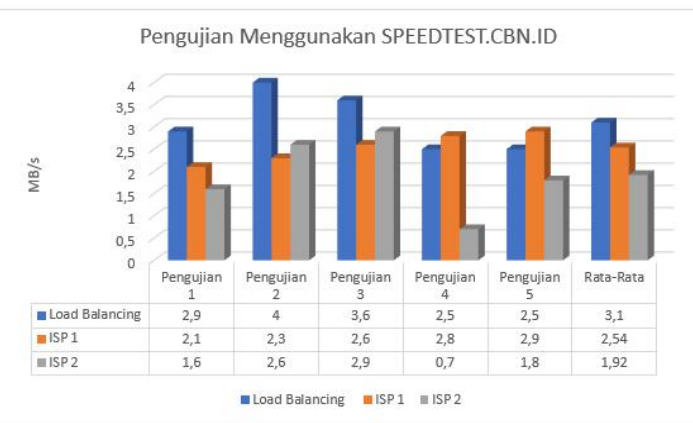

Gambar 7. Hasil Pengujian dengan Speedtest.cbn.id

Dari data hasil pengujian di atas, pengujian 1, pengujian 2, dan pengujian 3, sistem load balancing memiliki nilai throughput lebih besar dibandingkan dengan ISP 1 dan ISP 2. Sedangkan pengujian 4 dan pengujian 5, load balancing memiliki nilai throughput lebih kecil dibandingkan dengan ISP 1 dan ISP 2. Setelah dihitung nilai rata-rata throughput, didapatkan load balancing memiliki nilai throughput lebih besar dibandingkan dengan ISP 1 dan ISP 2.

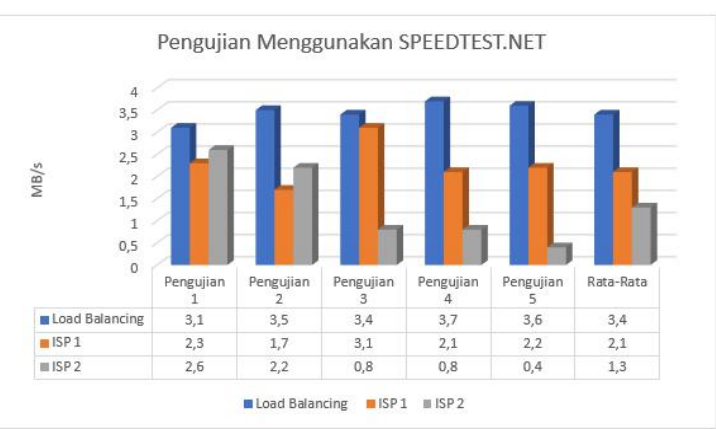

Gambar 8. Hasil Pengujian dengan Speedtest.net

Dari data hasil pengujian di atas, load balancing memiliki nilai throughput lebih besar dibandingkan dengan ISP 1 dan ISP 2 pada setiap pengujian. Sehingga, pada rata-rata, load balancing memiliki nilai throughput yang paling besar.

Berdasarkan pengujian yang dilakukan dengan kedua internet speed tester, sistem load balancing dapat berfungsi pada zeroshell yang terbukti dari nilai throughput sistem load balancing yang lebih besar dibandingkan dengan nilai throughput kedua ISP yang tidak menggunakan load balancing.

\section{B.Hasil Pengujian Load Balancing dengan Download Video}

Pengujian load balancing dengan download video dilakukan untuk mendapatkan nilai QoS, yaitu throughput, packet loss, delay, dan jitter.
TABEL V. HASIL PENGUJIAN DENGAN DOWNLOAD VIDEO

\begin{tabular}{|c|c|c|c|c|c|c|}
\hline \multirow{2}{*}{ QoS } & \multicolumn{5}{|c|}{ Pengujian ke- } & \multirow{2}{*}{$\begin{array}{r}\text { Rata- } \\
\text { Rata } \\
\end{array}$} \\
\hline & 1 & 2 & 3 & 4 & 5 & \\
\hline $\begin{array}{l}\text { Throughput } \\
\text { (Mbps) }\end{array}$ & 0,25 & 0,29 & 0,25 & 0,28 & 0,26 & 0,27 \\
\hline $\begin{array}{c}\text { Packet Loss } \\
(\%)\end{array}$ & 0 & 0 & 0 & 0 & 0 & 0 \\
\hline $\begin{array}{c}\text { Delay } \\
(\mathrm{ms})\end{array}$ & 4,63 & 4,05 & 5,23 & 4,24 & 4,44 & 4,52 \\
\hline $\begin{array}{l}\text { Jitter } \\
(\mathrm{ms})\end{array}$ & 5,47 & 4,83 & 5,91 & 5 & 5,41 & 5,32 \\
\hline
\end{tabular}

Data di atas merupakan hasil pengujian yang dilakukan sebanyak lima kali. Nilai rata-rata setiap parameter QoS disesuaikan dengan standar TIPHON untuk menentukan kategori dan indeks dari hasil pengujian (TABEL VI).

TABEL VI. HASIL PENGUJIAN SESUAI STANDAR TIPHON

\begin{tabular}{cccc}
\hline \multirow{2}{*}{ QoS } & \multirow{2}{*}{ Nilai } & \multicolumn{2}{c}{ Standar TIPHON } \\
\cline { 3 - 4 } & & Kategori & Indeks \\
\hline Throughput $(\mathrm{Mbps})$ & 0,27 & Sangat Bagus & 4 \\
\hline Packet Loss $(\%)$ & 0 & Sangat Bagus & 4 \\
\hline Delay $(\mathrm{ms})$ & 4,52 & Sangat Bagus & 4 \\
\hline Jitter $(\mathrm{ms})$ & 5,32 & Bagus & 3 \\
\hline
\end{tabular}

Dari data di atas, berdasarkan standar TIPHON, nilai throughput memiliki kategori "sangat bagus" dengan indeks 4. Nilai packet loss memiliki kategori "sangat bagus" dengan indeks 4 . Nilai delay memiliki kategori "sangat bagus" dengan indeks 4. Nilai jitter memiliki kategori "bagus" dengan indeks 3 .

\section{Hasil Pengujian Failover}

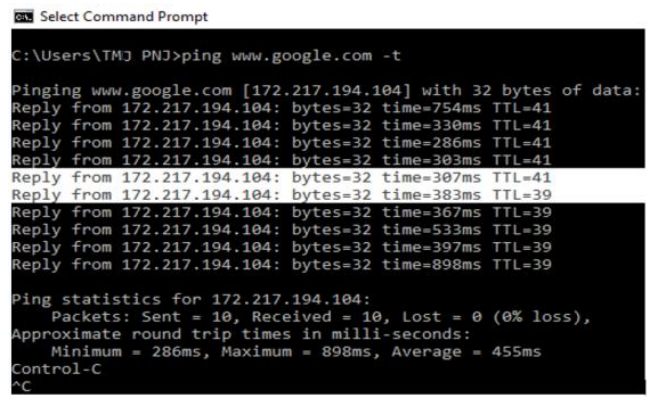

Gambar 9. Pengujian Failover pada Zeroshell

Gambar 9 merupakan pengujian failover yang dilakukan dengan melakukan ping ke web google.com dengan pengiriman data sebesar 32 byte. Saat proses ping berlangsung, satu jalur koneksi dimatikan untuk mendapatkan fungsi dari failover. TTL (Time To Live) terlihat berubah dari 41 menjadi 39 menandakan pengiriman paket yang terjadi sudah pada jaringan yang berbeda. 


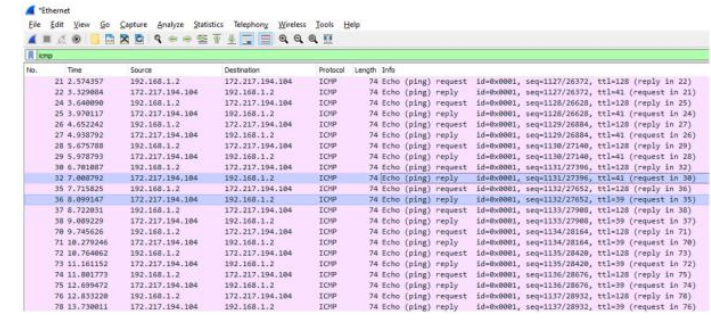

Gambar 10. Hasil Capture Packet dengan Wireshark

Nilai delay didapatkan dari pengurangan dua time since reference, yaitu 8,099147 second 7,008792 second $=1,0090355$ second.

TABEL VII. HASIL PENGUJIAN DELAY

\begin{tabular}{ccccccc}
\hline \multirow{2}{*}{ QoS } & \multicolumn{5}{c}{ Pengujian ke- } & $\begin{array}{c}\text { Rata- } \\
\text { Rata }\end{array}$ \\
\cline { 2 - 6 } & 1 & 2 & 3 & 4 & 5 & \\
\hline $\begin{array}{c}\text { Delay } \\
\text { (ms) }\end{array}$ & 1090 & 2150 & 2270 & 1070 & 3050 & 1926 \\
\hline
\end{tabular}

Data di atas merupakan hasil pengujian yang dilakukan sebanyak lima kali. Nilai rata-rata setiap parameter QoS disesuaikan dengan standar TIPHON untuk menentukan kategori dan indeks dari hasil pengujian (TABEL VIII).

TABEL VIII. NILAI DELAY SESUAI STANDAR TIPHON

\begin{tabular}{cccc}
\hline \multirow{2}{*}{ QoS } & \multirow{2}{*}{ Nilai } & \multicolumn{2}{c}{ Standar TIPHON } \\
\cline { 3 - 4 } & & Kategori & Indeks \\
\hline Delay $(\mathrm{ms})$ & 1926 & Jelek & 1 \\
\hline
\end{tabular}

Dari data di atas, berdasarkan standar TIPHON, nilai delay memiliki kategori "jelek" dengan indeks 1 .

\section{KESIMPULAN DAN SARAN}

Berdasarkan pengujian yang telah dilakukan, maka dapat diambil kesimpulan sebagai berikut:

1. Sistem load balancing dan failover dapat berfungsi pada zeroshell 3.9.3.

2. Sistem yang menerapkan load balancing memiliki throughput lebih besar dibandingkan dengan sistem yang tidak menerapkan load balancing.

3. Nilai throughput sistem load balancing pada zeroshell 3.9.3 memiliki kategori TIPHON "sangat bagus" dengan indeks 4.

4. Nilai packet loss sistem load balancing pada zeroshell 3.9.3 memiliki kategori TIPHON "sangat bagus" dengan indeks 4 .

5. Nilai delay sistem load balancing pada zeroshell 3.9.3 memiliki kategori TIPHON "sangat bagus" dengan indeks 4 .

6. Nilai jitter sistem load balancing pada zeroshell 3.9.3 memiliki kategori TIPHON "bagus" dengan indeks 3.

7. Nilai delay sistem failover pada zeroshell 3.9.3 memiliki kategori TIPHON "jelek" dengan indeks 1 .
Berdasarkan hasil penelitian yang telah dilakukan, perlu dilakukan peningkatan analisis untuk mendapatkan hasil evaluasi yang lebih optimal. Berikut adalah saran yang dapat dilakukan:

1. Menambahkan skenario pengujian sistem load balancing dengan 2 ISP untuk menentukan kapasitas beban yang digunakan pada masingmasing jalur ISP saat load balancing digunakan.

2. Menggunakan standar QoS yang berbeda sebagai pembanding standar QoS satu dengan yang lain untuk mendapatkan kategori dan indeks yang variatif.

\section{REFERENSI}

[1] N. Fauzi, W. Yahya, and A. Bhawiyuga, "Implementasi Load Balancing Pada Server Dengan Menggunakan Algoritme Least Traffic Pada Software-Defined Network," J. Pengemb. Teknol. Inf. dan Ilmu Komput. Univ. Brawijaya, vol. 2, no. 9, pp. 3134-3141, 2018.

[2] H. Nasser and T. Witono, "Analisis Algoritma Round Robin, Least Connection, Dan Ratio Pada Load Balancing Menggunakan Opnet Modeler," J. Inform., vol. 12, no. 1, pp. 25-32, 2016.

[3] H. Stipp, "Number of Internet Users Worldwide from 2005 to 2019,", 2019. https://www.statista.com/statistics/273018/number-ofinternet-users-worldwide (accessed Jan. 21, 2020).

[4] Miniwatts Marketing Group, "World Internet Usage and population $\quad$ statistics," 2019. https://www.internetworldstats.com/stats.htm (accessed Jan. 21, 2020).

[5] D. Darmawan and T. Imanto, "Analisa Link Balancing dan Failover 2 Provider Menggunakan Border Gateway Protocol (BGP) Pada Router Cisco 7606s," J. Nas. Teknol. dan Sist. Inf., vol. 3, no. 3, pp. 326-333, 2017.

[6] Suryanto, T. Prasetyo, and N. Hikmah, "Implementasi Load Balancing Menggunakan Metode Per Connection Classifier (PCC) Dengan Failover Berbasis Mikrotik Router," Semin. Nas. Inov. dan Tren, vol. 1, no. 1, pp. 230-238, 2018.

[7] R. Rasna and A. Ashari, "Application of Load Balancing with the Nth Method on Multiple Gateway Internet Networks," IJCCS (Indonesian J. Comput. Cybern. Syst., vol. 13, no. 2, pp. 159-168, 2019.

[8] A. Frayogi, W. Yahya, and R. A. Setiawan, "Perbandingan Kinerja RouterOS Mikrotik dan Zeroshell pada Mekanisme Load Balancing Serta Failover," J. Pengemb. Teknol. Inf. dan Ilmu Komput., vol. 2, no. 7, pp. 2689-2697, 2018.

[9] P. Oktivasari and R. Sanjaya, "Implementasi Sistem Load Balancing Dua ISP Menggunakan Mikrotik dengan Metode Per Connection Classfier," Multinetics, vol. 1, no. 2, pp. 33-37, 2015.

[10] M. Rosalia, R. Munadi, and R. Mayasari, "Implementasi HigRosalia, M., Munadi, R., \& Mayasari, R. (2016). Implementasi High Availability Server Menggunakan Metode Load Balancing dan Failover pada Virtual Web Server Cluster. E-Proceeding of Engineering, 3(3), 44964503.h Availability Server Menggu," e-Proceeding Eng., vol. 3, no. 3, pp. 4496-4503, 2016.

[11] S. R.S and B. R. Yashwantrao, "Load Balancing and its Algorithms in Cloud Computing: A Survey," Int. J. Comput. Sci. Eng., vol. 2, no. 1, pp. 95-100, 2017.

[12] A. P. Rofiatul Laily Siregar, "Implementasi Jaringan Hotspot dengan Captive Portal Zeroshell dan User Management LDAP," J. Manaj. Inform., vol. 9, no. 2, pp. 87-96, 2019.

[13] T. Pratama, M. A. Irwansyah, and Yulianti, "Perbandingan Metode PCQ, SFQ, RED Dan FIFO Pada Mikrotik Sebagai Upaya Optimalisasi Layanan Jaringan Pada Fakultas 
Teknik Universitas Tanjungpura," J. Tek. Inform. Univ. Tanjungpura, vol. 3, no. 3, pp. 298-303, 2015. 